shifts as a function of nucleotide concentration are difficult to interpret with any certainty, but tend to start again the hare of a functional heterogeneity of sites-that is to say interaction between the two myosin heads.

\section{ENVIRONMENT}

\section{Contamination by Lead}

from a Correspondent

A CONFERENCE on lead in the environment which was organized by the Institute of Petroleum in association with the Chemical Society and the British Occupational Hygiene Society in London on January 27 provided a unique opportunity in Britain for a discussion on a wide range of problems related to the nature, distribution and consequences of environmental lead. The meeting was opened by Sir Eric Ashby, chairman of the Royal Commission on Environmental Pollution.

Mr R. L. Stubbs (Lead and Zinc Development Association) reviewed the importance of the various forms of lead used and pointed out that large quantities of the scrap metal are recycled. With respect to the contamination of the environment he referred in particular to lead used in gasoline, the combustion of coal and other natural products, and the release of lead during its fabrication.

Professor P. J. Lawther, Dr B. T. Commins, Dr J. McK. Ellison and $\mathrm{Mr}$ B. Biles (Medical Research Council's Air Pollution Research Unit, London) presented their recent results of measurements of airborne concentrations of lead, the visual appearance under the electron microscope of lead containing particles emitted from engines and information related to a limited study of the blood lead content of London taxi drivers. They found that the concentration of particulate lead in one busy street was about twice that found nine years earlier, but that measurements at a site away from a street indicated for the past six years a possible decline in airborne lead there. In another study measurements indicated that only about one third of the airborne lead at a site away from a street was attributable to the motor vehicle. An examination of the extremely small particles from engines indicated that published information on the deposition, retention and uptake of airborne lead could not be applied to these special particles.

Drs L. H. P. Jones and C. R. Clements (Grassland Research Institute) showed that the uptake of grasses grown in soils containing lead is small and concluded that man's dietary intake of lead from this source is low because animals absorb little lead from grass and that which is absorbed accumulates in bone.

Dr H. Egan (Laboratory of the Government Chemist) presented information relating to the lead content of soil, vegetation and foodstuffs. $\mathrm{He}$ concluded that since 1940 there was no evidence that the amount of lead in the British diet had changed substantially.

Dr R. I. McCallum (Nuffield Department of Health, Newcastle) reviewed the modes of lead absorption and intoxication and the laboratory tests for assessing the effects on health following excessive exposure to lead. He concluded that for the general population there seemed to be no sound medical evidence to support clinical or subclinical lead poisoning.

Dr D. Barltrop (St Mary's Hospital, London) reviewed the environmental exposure to children and the behavioural factors which arise from excessive lead intake. He concluded for children that lead inhaled from the atmosphere is small by comparison with other sources of lead-for example, the chewing of lead containing paint and the ingestion of lead containing dust.

In the two and a half hours of general discussion the topics debated included (a) the interpretation of concentrations of lead found in the atmosphere in terms of vehicular movement and meteorological factors; (b) the financial and technological consequences of removing lead from petrol; (c) the relevance of industrially accepted exposure levels in relation to the air breathed by the general public; and (d) the need for further monitoring of the environmental lead including additional tests on the blood of British children. It was clear from the meeting that a great deal of information about lead is already known.
VIRAL TRANSFORMATION

\section{Genefics of Control}

from our Cell Biology Correspondent

THE temperature sensitive mutant strains of polyoma virus and Rous sarcoma virus which have been characterized respectively by Eckhart and Dulbecco and Martin clearly indicate that the maintenance of the transformed-cell phenotype of mammalian and avian fibroblasts transformed by these viruses depends on the continued expression of at least one viral gene. Viral transformation is not a hit and run affair, neither is the persistence of the viral genome without its partial expression sufficient to maintain transformation. It would, however, be unwise to assume from these observations that the properties which distinguish virus-transformed from untransformed cells are under the immediate control of the viral genome. Indeed Renger and Basilico (Proc. US Nat. Acad. Sci., 69, 109; 1972) have now reported an intriguing set of experiments which strongly suggest that the maintenance of several diagnostic properties of transformed cells depends on the continued expression of some cellular gene(s).

Instead of mutagenizing stocks of transforming virus before screening for temperature sensitive mutations which affect the transformed cell phenotype, Renger and Basilico took mouse 3T3 cells transformed by presumably wild type SV40 virus and, by a selective killing procedure, selected for cells which behave at $32^{\circ} \mathrm{C}$ as typical transformants, at least as far as cell multiplication in dense cultures is concerned, but which at $39^{\circ} \mathrm{C}$ behave in these conditions as untransformed cells. In other words, they selected cells from populations of transformants which

\title{
Xenon Isotopes in Natural Gas
}

IN next Monday's Nature Physical Science (February 21) M. S. Boulos and $O$. K. Manuel of the Nuclear Chemistry Department, University of Missouri, show from analysis of the isotopic composition of xenon found in natural gas that plutonium-244 was at one time to be found on Earth and that the isotope was probably present when the Earth was formed.

Previous analysis of natural gas samples has been unable to show unambiguously that plutonium-244 contributed to the anomalous enrichment of some of the xenon isotopes found in natural gas because a longer lived spontaneously fissioning isotopeuranium-238 - also contributed to the xenon content. The work reported in this article is, however, sufficiently accurate for there to be no ambiguity, and although uranium-238 is shown to contribute to the xenon content, the observed distribution of the xenon isotopes cannot be described solely by the fission of uranium-238 and a contribution from another spontaneously fissioning isotope - plutonium-244 - is needed to explain the data.

Plutonium-244 has a half life of $6.55 \times 10^{10}$ year for spontaneous fission but its decay is dominated by its $8.2 \times 10^{7}$ year half life for decay by alpha emission. On fissioning it produces xenon isotopes of atomic mass between 131 and 136, and these isotopes are expected to be enriched in xenon that has been in contact with plutonium over that found in atmospheric xenon. Boulos and Manuel also find that xenon-129 is enriched in their gas samples. 